\title{
PENGGUNAAN METODE PROFILE MATCHING UNTUK PEMILIHAN EOSH CAPTAIN TERBAIK PADA PT.COCA-COLA INDONESIA
}

\author{
Riduan Syaiful Mashyur, Frieyadie \\ Program Studi Sistem Informasi \\ Sekolah Tinggi Manajemen Informatika dan Komputer Nusa Mandiri \\ www.nusamandiri.ac.id \\ riduan.syaiful@yahoo.com,frieyadie@nusamandiri.ac.id
}

\begin{abstract}
Environment, Occupational, Safety and Health (EOSH) Captain is an activity created by the Safety Officer at PT. Coca-Cola Indonesia. To determine the best EOSH Captain for the first time and is still influenced by the Subjective factor in assessing the prospective EOSH Captain, the safety officer is sometimes difficult to determine the best EOSH Captain, due to the lack of criteria so that the inaccuracy of assessment results in errors in determining the selection of EOSH Captain, constraints Another factor is the search for supporting data for the EOSH captain selection criteria is hampered, because the safety officer must focus on the job desk of his work, resulting in the length of the decision-making process. In this study, to overcome the above constraints, a method called the Profile Matching method is used. This Profile Matching method can process and compare the actual data value of a profile to be assessed with the expected profile value so that competency differences can be known. The purpose of this research is to accelerate the decision-making process. The assessment process will be more accurate, resulting in the determination of the selection of EOSH to be more precise and correct. The assessment process will be more accurate, resulting in the determination of the selection of EOSH to be more precise and correct. The results of calculations using the Profile Matching method above have obtained the greatest value and become the best EOSH captain is employee 17.
\end{abstract}

Keywords: Decision Support, Profile Matching Method, EOSH.

Intisari-Environment, Occupational, Safety and Health (EOSH) Captain adalah sebuah kegiatan yang di buat oleh Safety Officer di PT. Coca-Cola Indonesia. Untuk penentuan EOSH Captain terbaik baru pertama kali dilakukan dan masih dipengaruhi oleh factor Subjectif dalam melakukan penilaian pada calon EOSH Captain, safety officer pun terkadang sulit dalam menentukan EOSH Captain terbaik, karena kurangnya kriteria sehingga kurang akuratnya penilaian mengakibatkan kesalahan dalam penentuan pemilihan EOSH Captain, kendala lain yaitu factor pencarian data pendukung untuk criteria pemilihan EOSH captain terhambat, karena safety officer harus berfokus pada jobdesk pekerjaannya, sehingga mengakibatkan lamanya proses pengambilan keputusan. Pada penelitian ini, untuk mengatasi kendala diatas, digunakan sebuah metode dengan nama metode Profile Matching. Metode Profile Matching ini dapat memproses dan membandingkan antara nilai data aktual dari suatu profil yang akan dinilai dengan nilai profil yang diharapkan, sehingga dapat diketahui perbedaan kompetensinya. Tujuan penelitian ini diantaranya mempercepat proses pengambilan keputusan. Proses penilaian menjadi lebih akuran sehingga mengakibatkan penentuan pemilihan EOSH menjadi lebih tepat dan benar. Hasil perhitungan menggunakan metode Profile Matching diatas sudah di dapatkan nilai terbesar dan menjadi EOSH captain terbaik ialah karyawan 17

Kata Kunci: Penunjang Keputusan, Metode Profile Matching, EOSH.

\section{PENDAHULUAN}

Environment, Occupational, Safety and Health (EOSH) Captain adalah sebuah kegiatan yang di buat oleh Safety Office di PT. Coca-Cola Indonesia. Yang bertujuan meningkatkan produktivitas dan kualitas kerja, juga untuk meningkatkan keselamatan dan kesehatan kerja bahkan dari keselamatan dan kesehatan kerja inilah peningkatan produktivitas dan kualitas kerja tersebut dapat tercapai, oleh karena itu Safety Officer mengadakan kegiatan EOSH Captain Tersebut, EOSH captain bertugas menjadi dan mencontohkan cara kerja yang baik, aman dan memberikan rekomendasi perbaikan, untuk Pemilihan EOSH captain terbaik adalah sebuah langkah yang bertujuan memberikan Reward (Handayani, 2017), (Munawir \& Ardiansyah, 2017) dan juga apresiasi kepada karyawan yang telah mencontohkan cara kerja yang baik dan aman serta 
untuk memberikan motivasi dan semangat kerja terhadap karyawan lain (Fitriani, 2019). Terdapat 34 karyawan, akan tetapi tidak semua karyawan yang termasuk dalam kandidat OESH Captain, hanya terdapat 17 karyawan yang termasuk dalam kandidat EOSH Captain tetapi hanya 1 kandidat yang akan terpilih dalam pemilihan EOSH Captain terbaik.

Untuk penentuan EOSH Captain terbaik baru pertama kali dilakukan dan masih dipengaruhi oleh factor Subjectif (Abadi, Setiawan, \& Rudianto, 2017) dalam melakukan penilaian pada calon EOSH Captain, safety officer pun terkadang sulit dalam menentukan EOSH Captain terbaik, karena kurangnya kriteria sehingga kurang akuratnya penilaian mengakibatkan kesalahan dalam penentuan pemilihan EOSH Captain (Kusnadi, Martha, \& Saputra, 2017), kendala lain yaitu factor pencarian data pendukung untuk criteria pemilihan EOSH captain terhambat, karena safety officer harus berfokus pada jobdesk pekerjaannya, sehingga mengakibatkan lamanya proses pengambilan keputusan (Purwanto, 2017), (Ernawati, Hidayah, \& Fetrina, 2017), (Nashrullah Irfan, Abdillah, \& Renaldi, 2015).

Sebagai solusi kendala-kendala diatas untuk dipilih metode Profile Matching untuk melakukan pemilihan personal terbaik diantara beberapa orang yang terpilih. Metode ini dipilih karena mampu menyeleksi alternatif terbaik dari sejumlah alternatif, dalam hal ini alternatif yang dimaksudkan yaitu yang layak menjadi karyawan terbaik (Basri, 2017), (Angeline, 2018).

Tujuan penelitian ini diantaranya supaya tidak di pengaruhi oleh factor subjektif dalam pemilihan EOSH captain, supaya lebih akurasi penilaian yang baik pada pemilihan EOSH captain, dan proses pengambilan keputusan yang cepat dan tepat.

\section{BAHAN DAN METODE}

\section{Rancangan Penelitian}

Rancangan penelitian yang dilakukan pada penelitian ini dengan beberapa tahapan yang dilakukan seperti dibawah ini.

1. Identifikasi Masalah

Identifikasi masalah yang akan dijadikan sebagai pokok pembahasan yaitu menentukan kriteria Eosh Captain yang ada di PT. Coca-Cola Indonesia untuk menentukan Eosh Captain Terbaik.

2. Studi literatur

Dilakukan dengan mempelajari dan memahami teori-teori tentang sistem penunjang keputusan, Profile Matching dengan mengumpulkan literatur, jurnal nasional, browsing internet dan bacaan- bacaan yang ada kaitannya dengan topik baik berupa textbook atau paper.

\section{Pengumpulan Data}

Pengumpulan data yang dilakukan dengan dua (2) cara, yaitu observasi dan wawancara kepada Safety Officer di PT.Coca-Cola Indonesia.

4. Data Penelitian

Data yang didapat berupa informasi tentang kriteria dan bobot dari calon Eosh Captain yang diperoleh dari Safety Officer di PT.Coca-Cola Indonesia.

5. Analisa Data

Dalam penelitian ini menggunakan Profile Matching, yang dilakukan dengan mengumpulkan data dan hasil analisis untuk mendapatkan informasi yang harus disimpulkan.

6. Hasil Analisa Data Menggunakan Profile Maching

Setelah tahap analisis data pemilihan Eosh Captain terbaik dihasilkan suatu hasil analisis yang merupakan hasil dari suatu proses penelitian yang dilakukan.

7. Kesimpulan dan Saran

Kesimpulan merupakan tahapan akhir dari uraian proses penelitian dengan menyimpulkan hasil dari penelitian sistem pendukung keputusan dalam pemilihan Eosh Captain Terbaik menggunakan metode Profile Matching dan memberikan saran terhadap permasalahan yang ada.

\section{Instrumen Penelitian}

Penelitian ini menggunakan instrumen wawancara (interview) kepada Safety Officer PT.Coca-Cola Indonesia untuk mengetahui tentang kriteria dari calon Eosh Captain Terbaik tersebut. Data hasil wawancara tersebut dianalisa dan diproses secara deskriptif. Data tersebut meliputi data dari masing-masing EOSH Captain, seperti mengingatkan atau menegur tindakan tidak aman, menjadikan contoh cara yang baik dan aman, rekomendasi perbaikan, berprilaku baik (membuang sampah pada tempatnya), dan menjaga lingkungan agar tetap bersih.

\section{Pengumpulan Data}

Dalam penyusunan skripsi ini metode pengumpulan data yang digunakan ada 2 yaitu data primer dan data sekunder, berikut penjelasannya:

a) Observasi

Penulis melakukan pengamatan langsung di PT.Coca-Cola Indonesia terhadap alurp enentuan Eosh Captain.

b) Wawancara

Penulis melakukan Tanya jawab dengan Safety Officer untuk mengetahui alur dari Eosh Captain tersebut.

\section{Populasi dan Sampel Penelitian}


a) Populasi

Berdasarkan data yang didapat penulis dari PT.Coca-Cola Indonesia diketahui populasi karyawan terdapat 34 karywan.

b) Sampel Penelitian

Teknik pengambilan sampel menggunakan teknik sampel jenuh atau sering disebut total sampling yaitu seluruh populasi calonEOSH Captain.

\section{Metode Analisis Data}

Berikut metode Profile Maching analisis data yang digunakan dalam penelitian ini.

1. Mendefinisikan terlebih dahulu kriteriakriteria yang akan di jadikan sebagai tolak ukur penyelesaian masalah.

Tabel 1 Nilai Keterangan kriteria

\begin{tabular}{ll}
\hline \multicolumn{1}{c}{ Aspek } & \multicolumn{1}{c}{ Kriteria } \\
\hline Aspek & S1 : Berprilaku aman \\
& S2 : Menegur prilaku tidak aman \\
& S3 : Melaporkan kondisi tidak aman \\
\hline Aspek & L1 : Berprilaku bersih terhadap area \\
Lingkungan & kerja \\
Kerja & L2 : Berkontribusi dalam membuang \\
& sampah sesuai tempatnya \\
& L3 : Memberikan rokomendasi \\
& perbaikan \\
\hline Aspek & K1: Mengajak Berolahraga \\
Kesehatan & K2: Mengingatkan Pola Makan Sehat \\
Kerja & K3: Mencontohkan Istirahat \\
\hline Sumber: (Mashyur \& Frieyadie, 2019) \\
& Tabel 2 Skala penilaian \\
\hline Nilai & Keterangan \\
\hline 1 & Sangat Kurang \\
\hline 2 & Kurang \\
\hline 3 & Cukup \\
\hline 4 & Baik \\
\hline 5 & Sangat Baik \\
\hline
\end{tabular}

Sumber: (Mashyur \& Frieyadie, 2019)

2. Menghitung Nilai GAP antara profile subjek dengan profile yang dibutuhkan. GAP = Profil Karyawan - Profil Kriteria

\begin{tabular}{cccl}
\multicolumn{4}{c}{ Tabel 3 Tabel Perhitungan GAP } \\
\hline No & $\begin{array}{c}\text { Selisih } \\
\text { Nilai } \\
\text { (GAP) }\end{array}$ & $\begin{array}{c}\text { Bobot } \\
\text { Nilai }\end{array}$ & \multicolumn{1}{c}{ Keterangan } \\
\hline 1 & 0 & 5 & $\begin{array}{l}\text { Tidak ada selisih (sesuai } \\
\text { dengan } \\
\text { dibutuhkan) }\end{array}$ \\
\hline 2 & 1 & 5,5 & $\begin{array}{l}\text { Kompetensi individu } \\
\text { lebih 1 tingkat/ level }\end{array}$ \\
\hline 3 & -1 & 4 & Kompetensi individu \\
\hline
\end{tabular}

\begin{tabular}{cccl}
\hline No & $\begin{array}{c}\text { Selisih } \\
\text { Nilai } \\
\text { (GAP) }\end{array}$ & $\begin{array}{c}\text { Bobot } \\
\text { Nilai }\end{array}$ & \multicolumn{1}{c}{ Keterangan } \\
\hline 4 & 2 & 4,5 & $\begin{array}{l}\text { kurang 1 tingkat/ level } \\
\text { Kompetensi individu } \\
\text { lebih 2 tingkat/ level }\end{array}$ \\
\hline 5 & -2 & 3 & $\begin{array}{l}\text { Kompetensi individu } \\
\text { kurang 2 tingkat/ level }\end{array}$ \\
\hline 6 & 3 & 3,5 & $\begin{array}{l}\text { Kompetensi individu } \\
\text { lebih 3 tingkat/ level }\end{array}$ \\
\hline 7 & -3 & 2 & $\begin{array}{l}\text { Kompetensi individu } \\
\text { kurang 3 tingkat/ level }\end{array}$ \\
\hline 8 & 4 & 2,5 & $\begin{array}{l}\text { Kompetensi individu } \\
\text { lebih 4 tingkat/ level }\end{array}$ \\
\hline 9 & -4 & 1 & $\begin{array}{l}\text { Kompetensi individu } \\
\text { kurang 4 tingkat/ level }\end{array}$ \\
\hline
\end{tabular}

Sumber: (Mashyur \& Frieyadie, 2019)

3. Menghitung Nilai Mapping GAP yang bersumber dari analisis GAP.

Adapun rumus menghitung nilai rata-rata Core Factor dan Secondary Factor sebagai berikut:

$N C F=\frac{\sum N C}{\sum I C}$

$N S F=\frac{\sum N S}{\sum I S}$

Dimana:

NCF : Nilai Rata-rata Core Factor

NSF : Nilai Rata-rata Secondary Factor

NC : Jumlah Total Nilai Core Factor

IC : Jumlah Total Nilai Item Core Factor

NS : Jumlah Total Nilai Secondary Factor

IS : Jumlah Total Nilai Item Secondary Factor

\section{Menghitung nilai akhir}

Setelah selesai melakukan perhitungan core factor dan secondary factor, maka tahap selanjutnya yang dilakukan adalah melakukan perhitungan nilai akhir atau total berdasarkan persentase dari core factor dan secondary factor yang diperkirakan berpengaruh terhadap penilaian karyawan. Rumus untuk penentuan penilaian kinerja karyawan terbaik sebagai berikut:

$(\mathrm{X}) \% \times \mathrm{NCF}+(\mathrm{X}) \% \times \mathrm{NSF}=\mathrm{N}$

Keterangan:

NCF : Nilai rata-rata core factor

NSF : Nilai rata-rata secondary factor

$\mathrm{N} \quad$ : Nilai total dari aspek-aspek penelian

$(\mathrm{X}) \% \quad$ : Nilai persen yang diinputkan

\section{Melakukan perangkingan}

Setelah proses perhitungan nilai akhir seluruh aspek kandidat EOSH Captain terbaik, tahap selanjutnya yang dilakukan adalah tahap penentuan rangking. Dimana tahap ini merupakan tahap akhir dari profile matching. 


\section{HASIL DAN PEMBAHASAN}

Dari hasil perhitungan dari tiapa spek di atas kemudian dihitung nilai total berdasar presentasi dari core dan secondary yang diperkirakan berpengaruh terhadap kinerja tiap-tiap profil. Untuk lebih jelasnya penghitungan nilai total terlebih dahulu menentukan nilai persen yang di inputkan yaitu core factor $60 \%$ dan secondary factor 40\%. Kemudian nilai core factor dan secondary factor ini dijumlahkan sesuai rumus dan hasilnya dapat dilihat pada contoh perhitungan aspek kedisiplin dan aspek kerjasama.

Tabel 4. Perhitungan Nilai Total Aspek Safety

\begin{tabular}{|c|c|c|c|c|}
\hline \multicolumn{5}{|c|}{ Tabel Total Gap Safety } \\
\hline No & Nama Karyawan & $\mathrm{CF}$ & SF & Ns \\
\hline 1 & KR1 & 3 & 5 & 3,8 \\
\hline 2 & KR2 & 4 & 4 & 4 \\
\hline 3 & KR3 & 2 & 5 & 3,2 \\
\hline 4 & KR4 & 4,5 & 3 & 3,9 \\
\hline 5 & KR5 & 2 & 3 & 2,4 \\
\hline 6 & KR6 & 4 & 3 & 3,6 \\
\hline 7 & KR7 & 2,5 & 4 & 3,1 \\
\hline 8 & KR8 & 3,5 & 5 & 4,1 \\
\hline 9 & KR9 & 3 & 2 & 2,6 \\
\hline 10 & KR10 & 2,5 & 4 & 3,1 \\
\hline 11 & KR11 & 3 & 3 & 3 \\
\hline 12 & KR12 & 3,5 & 3 & 3,3 \\
\hline 13 & KR13 & 2 & 4 & 2,8 \\
\hline 14 & KR14 & 4 & 5 & 4,4 \\
\hline 15 & KR15 & 3,5 & 4 & 3,7 \\
\hline 16 & KR16 & 3 & 5 & 3,8 \\
\hline 17 & KR17 & 5 & 3 & 4,2 \\
\hline
\end{tabular}

Sumber: (Mashyur \& Frieyadie, 2019)

Tabel 5. Perhitungan Nilai Total Aspek Lingkungan Kerja

\begin{tabular}{rcrrr}
\hline \multicolumn{5}{c}{ Tabel Total Gap Lingkungan Kerja } \\
\hline No & Nama Karyawan & CF & SF & Nlk \\
\hline 1 & KR1 & 3,5 & 2 & 2,9 \\
\hline 2 & KR2 & 4 & 5 & 4,4 \\
\hline 3 & KR3 & 3 & 3 & 3 \\
\hline 4 & KR4 & 4 & 4 & 4 \\
\hline 5 & KR5 & 2,5 & 4 & 3,1 \\
\hline 6 & KR6 & 4 & 3 & 3,6 \\
\hline 7 & KR7 & 4 & 2 & 3,2 \\
\hline 8 & KR8 & 5 & 3 & 4,2 \\
\hline 9 & KR9 & 3 & 4 & 3,4 \\
\hline
\end{tabular}

\begin{tabular}{lrrrr}
\hline \multicolumn{5}{c}{ Tabel Total Gap Lingkungan Kerja } \\
\hline 10 & KR10 & 3,5 & 4 & 3,7 \\
\hline 11 & KR11 & 3,5 & 5 & 4,1 \\
\hline 12 & KR12 & 5 & 3 & 4,2 \\
\hline 13 & KR13 & 3 & 2 & 2,6 \\
\hline 14 & KR14 & 5 & 4 & 4,6 \\
\hline 15 & KR15 & 5 & 3 & 4,2 \\
\hline 16 & KR16 & 4,5 & 5 & 4,7 \\
\hline 17 & KR17 & 4,5 & 5 & 4,7 \\
\hline
\end{tabular}

Sumber: (Mashyur \& Frieyadie, 2019)

Tabel 6. Perhitungan Nilai Total Aspek Kesehatan Kerja

\begin{tabular}{|c|c|c|c|c|}
\hline \multicolumn{5}{|c|}{ Tabel Total Gap Kesehatan Kerja } \\
\hline No & Nama Karyawan & $\mathrm{CF}$ & SF & $\mathrm{Nkk}$ \\
\hline 1 & KR1 & 4,5 & 2 & 3,5 \\
\hline 2 & KR2 & 4 & 5 & 4,4 \\
\hline 3 & KR3 & 3,5 & 3 & 3,3 \\
\hline 4 & KR4 & 4,5 & 4 & 4,3 \\
\hline 5 & KR5 & 3,5 & 4 & 3,7 \\
\hline 6 & KR6 & 4,5 & 3 & 3,9 \\
\hline 7 & KR7 & 3 & 2 & 2,6 \\
\hline 8 & KR8 & 4,5 & 3 & 3,9 \\
\hline 9 & KR9 & 2,5 & 4 & 3,1 \\
\hline 10 & KR10 & 3,5 & 4 & 3,7 \\
\hline 11 & KR11 & 4 & 5 & 4,4 \\
\hline 12 & KR12 & 4 & 3 & 3,6 \\
\hline 13 & KR13 & 4 & 2 & 3,2 \\
\hline 14 & KR14 & 4 & 4 & 4 \\
\hline 15 & KR15 & 3,5 & 3 & 3,3 \\
\hline 16 & KR16 & 4,5 & 5 & 4,7 \\
\hline 17 & KR17 & 4,5 & 5 & 4,7 \\
\hline
\end{tabular}

Sumber: (Mashyur \& Frieyadie, 2019)

\section{Perhitungan Penentuan Rangking}

Hasil akhir dari proses ini adalah rangking dari EOSH Captain terbaik. Penentuan rangking mengacu pada hasil perhitungan tertentu. Perhitungan tersebut dapat ditunjukkan pada rumus di bawah ini:

$\mathrm{Ha}=(50) \% \mathrm{Ns}+(25) \% \mathrm{Nlk}+(25) \% \mathrm{Nkk}$

Keterangan:

Ha : Hasil akhir

Ns : Nilai Sefety

Nlk : Nilai Lingkungan Kerja

Nkk : Nilai Kesehatan Kerja

$(\mathrm{x}) \% \quad$ : Nilai persen yang diinputkan 
Berikut adalah tabel hasil akhir dan penentuan rangking EOSH Captain terbaik berdasarkan metode profile matching: Berikut adalah tabel hasil akhir dan penentuan ranking karyawan berprestasi:

Tabel 7. Perhitungan Penentuan Rangking

\begin{tabular}{|c|c|c|c|c|c|}
\hline No & Nama Karyawan & Ns & Nlk & Nkk & Skor \\
\hline 1 & KR1 & 3,8 & 2,9 & 3,5 & 3,5 \\
\hline 2 & KR2 & 4 & 4,4 & 4,4 & 4,2 \\
\hline 3 & KR3 & 3,2 & 3 & 3,3 & 3,2 \\
\hline 4 & KR4 & 3,9 & 4 & 4,3 & 4,0 \\
\hline 5 & KR5 & 2,4 & 3,1 & 3,7 & 2,9 \\
\hline 6 & KR6 & 3,6 & 3,6 & 3,9 & 3,7 \\
\hline 7 & KR7 & 3,1 & 3,2 & 2,6 & 3,0 \\
\hline 8 & KR8 & 4,1 & 4,2 & 3,9 & 4,1 \\
\hline 9 & KR9 & 2,6 & 3,4 & 3,1 & 2,9 \\
\hline 10 & KR10 & 3,1 & 3,7 & 3,7 & 3,4 \\
\hline 11 & KR11 & 3 & 4,1 & 4,4 & 3,6 \\
\hline 12 & KR12 & 3,3 & 4,2 & 3,6 & 3,6 \\
\hline 13 & KR13 & 2,8 & 2,6 & 3,2 & 2,9 \\
\hline 14 & KR14 & 4,4 & 4,6 & 4 & 4,4 \\
\hline 15 & KR15 & 3,7 & 4,2 & 3,3 & 3,7 \\
\hline 16 & KR16 & 3,8 & 4,7 & 4,7 & 4,3 \\
\hline 17 & KR17 & 4,2 & 4,7 & 4,7 & 4,5 \\
\hline
\end{tabular}

Sumber: (Mashyur \& Frieyadie, 2019)

Tabel 8. Hasil Rangking berdasarkan Metode Profile Matching

\begin{tabular}{|c|c|c|}
\hline No & Nama Karyawan & Skor \\
\hline 1 & Karyawan1 & 3,5 \\
\hline 2 & Karyawan2 & 4,2 \\
\hline 3 & Karyawan3 & 3,2 \\
\hline 4 & Karyawan4 & 4,0 \\
\hline 5 & Karyawan5 & 2,9 \\
\hline 6 & Karyawan6 & 3,7 \\
\hline 7 & Karyawan7 & 3,0 \\
\hline 8 & Karyawan8 & 4,1 \\
\hline 9 & Karyawan9 & 2,9 \\
\hline 10 & Karyawan 10 & 3,4 \\
\hline 11 & Karyawan11 & 3,6 \\
\hline 12 & Karyawan 12 & 3,6 \\
\hline 13 & Karyawan13 & 2,9 \\
\hline 14 & Karyawan14 & 4,4 \\
\hline 15 & Karyawan 15 & 3,7 \\
\hline 16 & Karyawan16 & 4,3 \\
\hline 17 & Karyawan 17 & 4,5 \\
\hline
\end{tabular}

Sumber: (Mashyur \& Frieyadie, 2019)

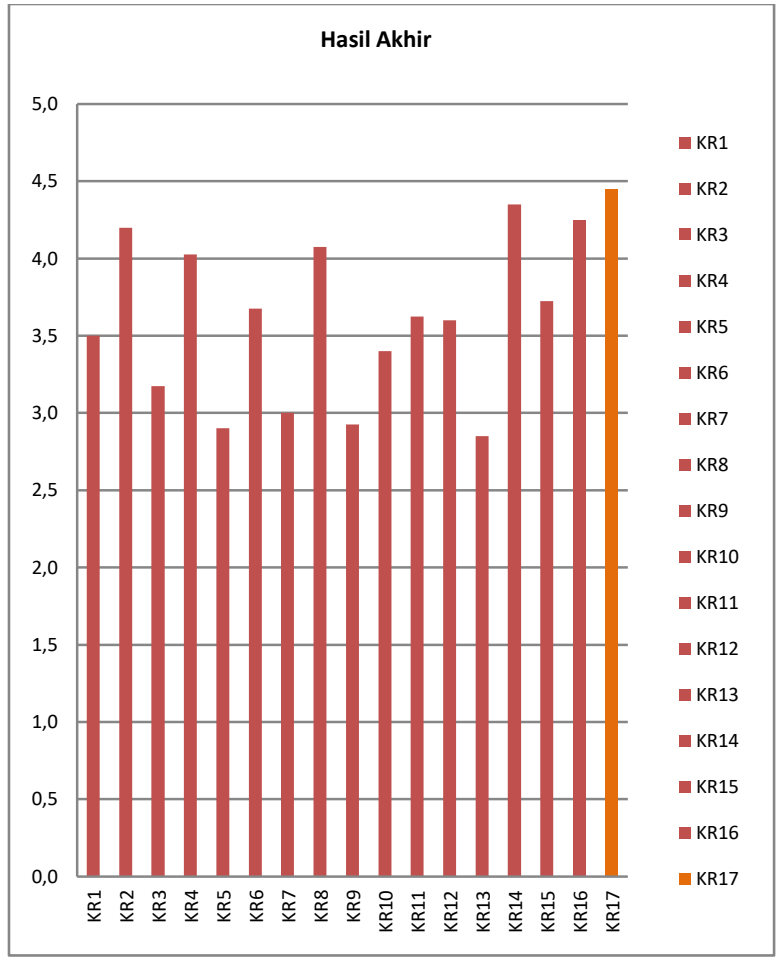

Sumber: (Mashyur \& Frieyadie, 2019)

Gambar 1. Grafik Hasil Akhir

Hasil perhitungan menggunakan metode Profile Matching diatas sudah di dapatkan nilai terbesar dan menjadi EOSH captain terbaik ialah karyawan 17 dengan menentukan GAP pada masing-masing eosh captain di lanjutkan dengan perhitungan mencari Bobot dari gap yang sudah ada selanjutnya dari gap yang sudah ada menentukan core factor dan secondary factor yang nantinya dari core factor dan secondary factor akan dihitung berdasarkan persentasi dari core factor yaitu $60 \%$ dan secondary factor $40 \%$ yang sudah di tentukan sebelumnya, dari sinilah penentuan nilai akhir sekor pada eosh captain dapat di tentukan dengan rumusan $\mathrm{Ha}=(50) \% \mathrm{Ns}$ $+(25) \% \mathrm{Nlk}+(25) \% \mathrm{Nkk}$ setelah perhitungan hasil akhir di dapatkanlah karyawan 17 sebagai karyawan yang memiliki nilai tertinggi dari perhitungan profile maching dan terpilih menjadi EOSH captain terbaik.

\section{KESIMPULAN}

Berdasarkan penelitian dari pembahasan yang telah penulis lakukan, maka dapat diambil beberapa kesimpulan, diantaranya: Metode Profile Matching dapat digunakan sebagai alternative Pengambilan keputusan dalam penentuan Eosh Captain terbaik pada PT. Coca-Cola Indonesia. Maka, penggunaan metode Profile Matching dapat membantu dalam menentukan suatu keputusan. Penentuan Variable nilai dari setiap aspek atau 
kriteria sangat berpengaruh dalam proses penentuan Eosh Captain terbaik. Berdasarkan analisa untuk penentuan Eosh Captain terbaik, maka untuk Hasil akhir perhitungan dari Nilai Rangking di dapatkan nilai tertinggi yaitu Karyawan 17 dengan nilai rengking 4.5.

Saran yang dapat disampaikan penulis untuk pengembangan sistem pendukung keputusan dalam menentukan Eosh Captain terbaik menggunakan Profile Matching, diantarnya: Untuk penelitian kedepannya dapat menambahkan aspek-aspek atau kriteria lain yang dibutuhkan dalam pemilihan Eosh Captain terbaik sehingga hasil akhir dari perhitungan dapat di maksimalkan sehingga hasil dari perhitungan lebih Objektif. Untuk mengurangi kesalahan di sarankan menggunakan alat bantu (software) dalam perhitungan penentuan Eosh Captain terbaik sehingga hasil akhir dari perhitungan lebih maksimal dan mengurangi kesalahan dalam manual perhitungan.

\section{REFERENSI}

Abadi, I., Setiawan, A., \& Rudianto, A. (2017). PROSIDING seminar nasional sisfotek Pengambilan Keputusan dalam Menentukan Rekomendasi Promosi Jabatan Struktural dengan Pendekatan Profile Matching di Biro Perekonomian Propinsi Jawa Barat, 3584, 8389.

Angeline, M. (2018). SISTEM PENDUKUNG KEPUTUSAN PEMILIHAN KARYAWAN TERBAIK MENGGUNAKAN METODE PROFILE MATCHING. STMB Multismart, II(2), 45-51.

Basri, B. (2017). METODE WEIGHTD PRODUCT (WP) DALAM SISTEM PENDUKUNG KEPUTUSAN PENERIMAAN BEASISWA PRESTASI. Jurnal INSYPRO (Information System and Processing), 2(1). https://doi.org/10.24252/INSYPRO.V2I1.247 4

Ernawati, E., Hidayah, N. A., \& Fetrina, E. (2017). RANCANG BANGUN SISTEM PENDUKUNG KEPUTUSAN KENAIKAN JABATAN PEGAWAI DENGAN METODE PROFILE MATCHING (Studi Kasus: Kementerian Agama Kantor Wilayah DKI Jakarta). Studia Informatika: Jurnal Sistem Informasi, 10(2), 127-134. https://doi.org/10.15408/SIJSI.V10I2.7760

Fitriani, D. (2019). SISTEM PENDUKUNG KEPUTUSAN PENENTUAN KARYAWAN TERBAIK PADA COLLECTION PT . PANIN BANK MENGGUNAKAN, 3(1), 1-8.
Handayani, R. I. (2017). BERPRESTASI DENGAN METODE PROFILE MATCHING PADA PT . SARANA INTI PERSADA ( SIP ). Jurnal Pilar Nusa Mandiri, 13(1), 28-34.

Kusnadi, K., Martha, D., \& Saputra, A. (2017). Penerapan Metode Profile Matching Untuk Penilaian Kenaikan Jabatan Karyawan (Studi Kasus: Pt. Ilham Bangun Mandiri). Jurnal Digit, 5(2), 146-158.

Mashyur, R. S., \& Frieyadie, F. (2019). Laporan Akhir Penelitian: Penggunaan Metode Profile Matching Untuk Pemilihan Eosh Captain Terbaik Pada PT.Coca-Cola Indonesia. Jakarta.

Munawir, M. ;, \& Ardiansyah, A. ; (2017). Decision Support System Pemilihan Karyawan Berprestasi Dengan Pendekatan Analisa Gap Profile matching Di Kantor Perwakilan Bank Indonesia Provinsi Aceh. Jurnal Teknologi Informasi Dan Komunikasi, 1(1), 7-14.

Nashrullah Irfan, M., Abdillah, G., \& Renaldi, F. (2015). Sistem Pendukung Keputusan untuk Rekomendasi Promosi Jabatan ... (Nashrullah dkk.). Sistem Pendukung Keputusan, 5(1), 196-201.

Purwanto, H. (2017). PENERAPAN METODE PROFILE MATCHING DALAM SISTEM PENDUKUNG KEPUTUSAN PENILAIAN KINERJA KARYAWAN PADA PT. HYUNDAI MOBIL INDONESIA CABANG KALIMALANG. Jurnal Techno Nusa Mandiri, 14(1), 15-20. 